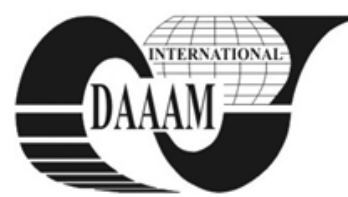

Annals of DAAAM for 2011 \& Proceedings of the 22nd International DAAAM Symposium, Volume 22, No. 1, ISSN 1726-9679 ISBN 978-3-901509-83-4, Editor B. Katalinic, Published by DAAAM International, Vienna, Austria, EU, 2011 Make Harmony between Technology and Nature, and Your Mind will Fly Free as a Bird Annals \& Proceedings of DAAAM International 2011

\title{
SUPPLY CHAIN RESILIENCE: A SIMULATION STUDY
}

\section{CARVALHO, H[elena]; BARROSO, A[na] P[aula]; MACHADO, V[irginia] H[elena]; AZEVEDO, S[usana] G[arrido] \& MACHADO, V[irgilio] C[ruz]}

\begin{abstract}
This paper aims to analyze the supply chain behavior when subject to disturbances using a simulation-based approach. The disturbance explored in this study is the transportation interruption between two suppliers in the automotive supply chain. The performance of the different supply chain entities is used to analyze supply chain design scenarios. The analysis of the outputs simulation study shows that even when a redundancy strategy is used, the negative effects of a disturbance are spread along the supply chain, but the resilience of supply chain entities is enhanced.
\end{abstract}

Key words: supply chain management, resilience, case study, simulation

\section{INTRODUCTION}

Rupture conditions in supply chains (SC) are observed when SC entities are subject to disturbances, caused by sudden and unforeseen events. An example of disturbance event is September 11, 2001, where the New York's World Trade Center Towers were destroyed by terrorist attack. Automakers like Ford and Toyota had to stop their production lines in US facilities due to part delays coming from foreign countries (Sheffi, 2001). Others types of less catastrophic but highly severe disturbances, could also occur; like the Robert Bosch $\mathrm{GmbH}$ example where in 2005 a quality defect in a small part supplied by another SC entity resulted in the recall of several thousands of cars (Wagner \& Bode, 2006). Once the SC is affected by a disturbance, its performance is jeopardized, that is, the short-term financial performance is reduced, with a loss of competitiveness ( $\mathrm{Ji} \& \mathrm{Zhu}, 2008)$. To sustain competitiveness, SC entities and their SCs must be resilient, i.e., they must develop their ability to react to unexpected events and to quickly return to their original state or move to a new state after being disturbed (Pettit et al., 2010).

The main objective of this paper is to analyze the SC behavior when subject to disturbances. To this end a simulation-based approach is proposed to observe SC behavior under different design scenarios. A case study related to the simulation of a Portuguese automotive SC is presented.

\section{SIMULATION STUDY}

To formulate adequate resilience strategies, it is necessary considering the disturbances that may lead to poor SC performance. The simulation models utilization is an effective method for considering the disturbances occurring in a SC context (Melnyk et al., 2009). The modeling process is crucial from the SC resilience perspective; the simulation model should provide adequate performance measures to assess the system behavior before and after the disturbance occurrence.

In this research, an exploratory case study was conducted at a Portuguese automotive SC. The automotive SC was selected since it is extremely vulnerable to disturbances (Thun \& Hoenig, 2011). The case study boundaries were defined after a preliminary interview with the automaker SC manager. The case study involves only a sub-set of the automotive SC (Figure 1). The metric fulfillment rate was selected to evaluate each SC entity performance. The following disturbance was pointed out as relevant to this study: material transportation interruption from Supplier 5 to Supplier 3, with duration of seven days.

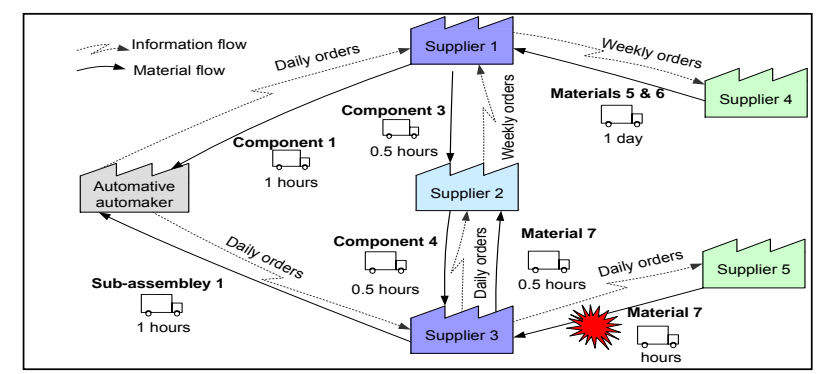

Fig. 1. Supply chain representation

To make easier the simulation development, an approach similar to Pundoor \& Herrmann (2006) was used. A set of modules was developed to model the Source, Make and Delivery processes based on the Supply Chain Operations Reference Model (Supply-Chain Council, 2009). The simulation model was developed using the simulation software Arena together with Microsoft Excel and Visual Basic for Applications. A total of 10 replications was determined by statistical analysis of the lead time. One simulation run is for 8 hours per day during a period of 60 days.

\section{RESULTS ANALYSIS AND DISCUSSION}

The following four SC scenarios have been developed: Scenario 1 - current SC design without disturbance; Scenario 2 - current SC design subject to the disturbance; Scenario 3- a redundancy SC design without disturbance; and Scenario 4 redundancy SC design subject to the disturbance. In scenarios 3 and 4 the same SC resilience strategy is modeled: the inventory level of Material 7 in Supplier 2 is increased from 3 to 7 days. All scenarios are subject to the same input values, namely, demand patterns, bill of material, inventory data, resource data, transportation time and cost data. As stated previously to assess the SC performance the simulation returns the fulfillment rate for each SC entity. Figure 2 contains the simulation outputs. In the scenarios without disturbance (Scenarios 1 and 3) it can be seen that all SC entities have some fluctuation in their behavior, arising from the day-to-day uncertainty in the processes.

When the SC is affected by a disturbance, in day 15 , with duration of 7 days, which causes an interruption in the transportation of Material 7 from Supplier 5 to Supplier 3, the plots have highlight in color grey the area corresponding to a lower performance. Scenario 2 shows clearly the inability of Supplier 5 to deliver Material 7 on-time to Supplier 3 when no resilience strategies are applied. The grey area in Supplier 5 plot clearly shows a decrease of performance after the disturbance occurrence. Plots of Suppliers 2 and 3 also 
evidence the lack of resilience of these entities. However, not all SC entities are affected by the disturbance. Supplier 1 and Supplier 4 maintain their normal behavior. Only when the disturbance fades away Supplier 5 is able to recover the initial state, delivering all the late orders at once, increasing the fulfillment rate. Supplier 3 is unable to deliver all the late orders at once, as it requires 4 days to restore its normal behavior. The behavior of the upstream entities will affect Supplier 2 suffering two waves of material shortage: the first caused by the disturbance, and the second when Supplier 3 delivers materials after the disturbance, since the recently delivered material will be used to produce late orders, leading to another stock-out situation.

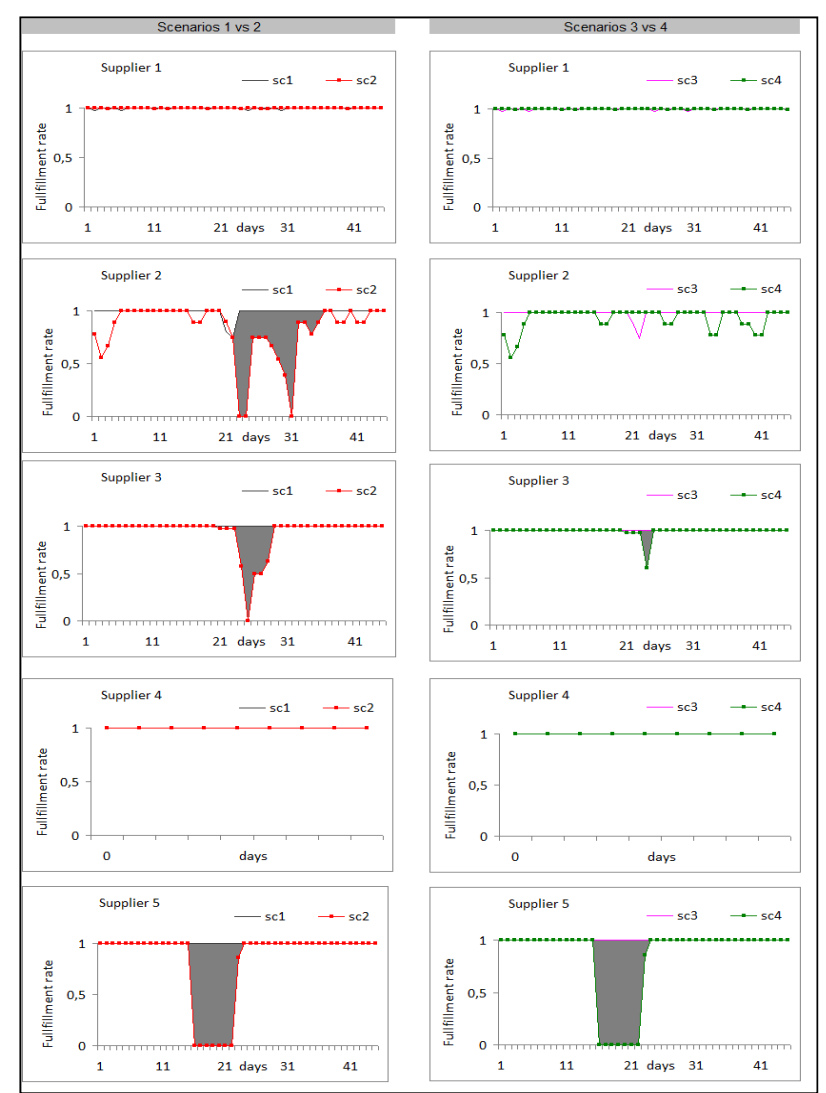

Fig. 2. Simulation results

In a SC design based on redundancy, Supplier 2 increases the safety stock to 7 days (Scenario 3), also increasing the inventory hold cost. If the disturbance occurs (Scenario 4), all SC entities are able to fulfill their customer needs, except Suppliers 5 and 3. In this situation Supplier 2 uses the safety stock to avoid a production stoppage and deliver the material on time. If the disturbance occurs, this strategy is effective in overcoming the negative effects, but two SC entities (Supplier 5 and Supplier 3) change their normal behavior, being affected by the disturbance negative effects. So, although the redundancy strategy reduces the disturbance impact it propagates its negative effects along the SC. These results are in line with the ones obtained by Tang \& Tomlin (2008) which propose flexibility as a means to reduce the disturbance negative effects, since the redundancies can hinder SC inefficiencies. The case study results also reveal some trade-offs in SC design, such as higher performance from having low inventory in the SC under normal operating conditions, but it increase the fragility during periods of disruption (Svensson, 2000).

\section{CONCLUSION}

This paper uses a simulation study to analyze the SC entities behavior when subject to a disturbance. Taking into account all the diversity associated with disturbances and cascading unexpected effects on SC behavior, in this paper the use of simulation is proposed as a tool to assist the design of SCs for resilience helping to visualize the negative effects of SC disturbance under diverse scenarios. The case study results show that even when a redundancy strategy is used, the disturbance negative effects are spread along the SC, but the resilience of SC entities is enhanced.

This study has several limitations. The research is related to the automotive SC and the findings may not be universally applicable across different sectors with different processes specificities. The main limitation is related to the system boundaries; only a small subset of the whole SC was considered. This represents an oversimplification of a real SC and the actual SC response to disturbances could be difficult to reveal. Moreover only one SC disruption had been modeled, an interruption in transportation. Consequently, future studies are needed to identify the main effects between SC resilience design and SC performance and the various moderating and mitigating factors. SC design for resilience remains an important but relatively under-studied area of SC.

\section{ACKNOWLEDGMENTS}

This research is funded by Fundação para a Ciência e Tecnologia (Project MIT-Pt/EDAM-IASC/0033/2008). The first author was supported by a $\mathrm{PhD}$ fellowship from Fundação para a Ciência e Tecnologia (SFRH/BD/43984/2008).

\section{REFERENCES}

Ji, G. \& Zhu, C. (2008). Study on supply chain disruption risk management strategies and model. Proceedings of 5th International Conference Service Systems and Service Management, ICSSSM'08, June 30-July 2, Melbourne, VIC, ISBN: 978-1-4244-1671-4, pp. 1 -6

Melnyk, S., Rodrigues, A. \& Ragatz, G. (2009). Using Simulation to Investigate Supply Chain Disruptions. In Supply Chain Risk, G. A. Zsidisin \& B. Ritchie, (Ed.), 103122, Springer US, ISBN: 978-0-387-79933-9, Boston, MA.

Pettit, T., Fiksel, J. \& Croxton, K. (2010). Ensuring supply chain resilience: development of a conceptual framework. Journal of Business Logistics, Vol. 31, No. 1, pp. 1-21

Pundoor, G. \& Herrmann, J. (2006). A hierarchical approach to supply chain simulation modelling using the Supply Chain Operations Reference model. International Journal of Simulation and Process Modelling, Vo. 2, No. 3/4, pp. 124132, ISNN: 17402123

Sheffi, Y. (2001). Supply chain management under the threat of international terrorism. The International Journal of Logistics Management, Vol. 12, No. 2, pp. 1-11

Supply-Chain Council, 2009. SCOR Overview, 9.0 version. Available at: http://supply-chain.org/

Svensson, G. (2000). A conceptual framework for the analysis of vulnerability in supply chains. International Journal of Physical Distribution \& Logistics Management, Vol. 30, No. 9, pp. 731-750, ISSN: 09600035

Tang, C. \& Tomlin, B. (2008). The power of flexibility for mitigating supply chain risks. International Journal of Production Economics, Vol. 116, No. 1, pp. 12-27, ISSN: 09255273

Thun, J. \& Hoenig, D. (2011). An empirical analysis of supply chain risk management in the German automotive industry. International Journal of Production Economics, Vol. 131, No. 1, pp. 242-249, ISSN: 09255273

Wagner, S. \& Bode, C., 2006. An empirical investigation into supply chain vulnerability. Journal of Purchasing and Supply Management, Vol. 12, No. 6, pp. 301-312, ISSN: 14784092 